\title{
Faculty Perspectives on Service-Learning in Engineering Education: Chal- lenges and Opportunities
}

\section{Dr. Bowa George Tucker, UMass Lowell}

Dr. Bowa George Tucker is a research fellow for the National Science Foundation-funded Engineering Faculty Engagement in Learning through Service and Engineering for the Common Good in the College of Engineering at the University of Massachusetts, Lowell. He received his doctorate from the University of Massachusetts-Boston in Higher Education Administration in 2010. Dr. Tucker has extensive experience in program management and evaluation of multi-year, multimillion dollar partnership programs. His expertise includes assessment in teaching and learning outcomes in k-12 and in higher education, diversity, leadership, community outreach, and curriculum development.

Prof. David O Kazmer, University of Massachusetts, Lowell

Dr. Olga Pierrakos, James Madison University

Dr. Olga Pierrakos is an associate professor and founding faculty member of the James Madison University Department of Engineering, which graduated its inaugural class in May 2012. At JMU, Dr. Pierrakos is the director of the Center for Innovation in Engineering Education (CIEE) and director of the Advanced Thermal Fluids Laboratory. Her interests in engineering education research center around recruitment and retention, engineer identity, engineering design instruction and methodology, learning through service, problem based learning methodologies, assessment of student learning, as well as complex problem solving. Her other research interests lie in cardiovascular fluid mechanics, sustainability, and K-12 engineering outreach. Dr. Pierrakos is a 2009 NSF CAREER Awardee. Dr. Pierrakos holds a B.S. in Engineering Science and Mechanics, an M.S. in Engineering Mechanics, and a Ph.D. in Biomedical Engineering from Virginia Tech.

Dr. Chris Swan, Tufts University

Dr. Angela R Bielefeldt, University of Colorado, Boulder

Dr. Angela Bielefeldt is a professor at the University of Colorado Boulder in the Department of Civil, Environmental, \& Architectural Engineering (CEAE). She is currently the associate chair for Undergraduate Education in CEAE and has served as the ABET assessment coordinator since 2008. She began incorporating service-learning (SL) projects into the capstone design course for environmental engineering in 2001. This began her journey to determine how to rigorously assess the learning outcomes for students who worked on SL projects as compared to other types of projects in the course. Her engineering education research interests include students' attitudes and knowledge about sustainable engineering, engineering ethics, and attracting and retaining women in engineering.

\section{Prof. Kurt Paterson P.E., Michigan Technological University}

Kurt Paterson is an associate professor of Civil and Environmental Engineering, and director of Michigan Tech's D80 Center which offers contribution-based learning, research and service opportunities for students with the poorest $80 \%$ of humanity. Dr. Paterson is a noted educator, workshop facilitator, and public speaker on community engagement, and leads several initiatives for learning engineering through service, recently leading ASEE's newest division, Community Engagement in Engineering Education. He is PI on several research projects assessing the impacts of community engagement on students, faculty, and communities around the world.

\section{Dr. Annie Soisson, Tufts University}

Dr. Annie Soisson is the associate director of the Center for the Enhancement of Learning and Teaching (CELT) at Tufts University. She works with faculty to foster teaching innovation and to facilitate improved learning outcomes for students. Her areas of interest are service learning, diversity, team teaching and interdisciplinary learning. She earned graduate degrees in education from the Harvard Graduate School of Education and Boston University. 


\title{
Faculty Perspectives on Learning through Service in Engineering Education: Challenges and Opportunities
}

\begin{abstract}
Learning through Service (LTS) is an umbrella term that includes, both curricular and extracurricular activities, reflecting that there are many models that exist currently for how faculty use opportunities for students to learn while providing service to a community. Over the past decade, Learning through Service has proliferated in higher education as an effective teaching and learning method. As the pedagogy continues to gain momentum, and many colleges and universities in the United States have designed their engineering curriculum and extra-curricular activities to include experiential learning, including service-learning.

Nevertheless, despite the curriculum overhaul and increase in the use of LTS in engineering, there have been limited studies to evaluate the reasons for faculty interest in LTS and their experiences.
\end{abstract}

In 2011, investigators from Tufts University, James Madison University, Michigan Technological University, the University of Colorado Boulder, and the University of Massachusetts Lowell were awarded a grant from the National Science Foundation to evaluate the experience and motivations of faculty currently engaged in LTS efforts; and to empower additional faculty to implement LTS. Expectations included interviewing faculty engaged in LTS efforts in engineering in order to understand their motivations, and what teaching, learning and assessment methodologies they use to enhance engineering education.

The purpose of this study is to: a) understand why engineering faculty engage their students in LTS, and b) understand how engineering faculty implement LTS initiatives. (This study explores faculty efforts in both service-learning and community service). This study is focused on engineering faculty members who integrate LTS efforts in engineering across a broad range of institutions of higher education. Twenty-nine interviews were conducted with engineering LTS practitioners to explore their interests, challenges, and results of their efforts. Analysis of the interview transcripts reveals 1) faculty members who are passionate about LTS tend to play a leading role in promoting LTS within their institution; 2) faculty's primary interest in integrating LTS is predominantly motivated by a desire to improve the quality of their teaching and student learning; 3) faculty consistently encounter challenges related to course design, resource limitations, increased workload, and lack of adequate support from their institutions. The discussion in this paper focuses on the areas that appear to limit the effectiveness of their LTS efforts and directions for future research.

\section{Introduction}

In the past decade, there has been numerous calls to reform engineering education in the United States to foster increased student understanding of the impact of engineering solutions in a global societal context. ${ }^{1}$ In light of these efforts, attention has focused on: (1) curricular reform to improve undergraduate engineering education, and (2) the instruction students should receive to become productive and socially responsible engineers. ${ }^{2}$ This focus has not only shifted how engineering students are taught necessary technical skills to address the demands of rapidly changing technologies, but also toward developing the skills essential as citizens in a globalized world. 
Vanasupa et al. argue that social responsibility is at the heart of the Engineer's Creed. ${ }^{3}$ They believe that engineering curriculum should go beyond developing technical knowledge and should take a socially responsible approach that takes into account the ethical, social, and environmental impact of engineering solutions. With this increased focus on preparing engineering students to be socially responsible, faculty members are challenged to develop curricular and extracurricular activities to enable their students to achieve learning outcomes essential in addressing the challenges of the twenty-first century such as globalization, climate change, sustainability, and inequality. ${ }^{4,5}$

To meet this wider challenge, many colleges and universities have increased community based experiential learning opportunities for engineering students through curricular and extracurricular programs. ${ }^{4,6-10}$ This learner-centered approach is jointly constructed by students, community members and the faculty. ${ }^{11,12}$ It is a democratic learner-centered approach in which students work in collaboration with the each other, community members and their instructors to solve problems.

Learning Through Service (LTS) provides a platform for interactive participatory student involvement in their own learning. It is an umbrella term that includes, both curricular and extracurricular activities, and reflects that there are many models that exist currently for how faculty use opportunities for students to learn while providing service to a community. One of the better known and effective models, service-learning is a curricular teaching method in which students participate in organized service activity for academic credit that meets identified community issues, and that reflection done by the students on their service experience furthers their understanding of course content. ${ }^{13-19}$ In addition, there are many extracurricular activities that include global learning opportunities, such as, Engineers without Borders. The programs are not necessarily part of the curriculum, but provide rich opportunities for students to learn through service. Both curricular activities including service-learning and extracurricular activities such as Engineers without Borders are forms of community service with learning goals.

Hepburn states that, the difference between community service and service-learning is that "service-learning is a particular form of community service that is curriculum-based," whereas "community service is broadly used to describe all types of service including individual and organized volunteer work that is not part of the school curriculum" (p.47). The term LTS was developed to recognize that there are a range of community based service activities that faculty use to provide valuable learning experiences for students while fostering social responsibility. ${ }^{20}$

In spite of the growing call to reform engineering curriculum to include experiential learning opportunities to develop socially-active students, it is not clear that much progress has been made in this area. While some studies have been conducted to examine the integration of learning through service in engineering. ${ }^{21-23}$ Huilman studied engineering faculty from diverse institutions of higher education to discern what motivates them to use LTS in engineering, and what challenges they face in the process. ${ }^{24}$ 


\section{Research Method}

Yin posits that case study is the preferred strategy when "how or why" questions are being posed. ${ }^{25}$ Furthermore, he suggests that the case study method is used in many situations to contribute to understanding individuals, groups, and organizational, social, political, and related phenomena. Therefore, case study as a qualitative research technique is used for this study primarily because it provides "a detailed account of the phenomenon under study". ${ }^{26}$ In-depth interviews of 27 engineering faculty members were conducted using a structured protocol to uncover the personal stories of what motivated them to get involved in LTS efforts and the challenges they faced in the process, to discover how their stories intersect.

Participants were each interviewed once. Eleven of the interviews were conducted face-to-face for approximately forty-five minutes at an NSF-sponsored workshop, and the rest of the interviews were conducted over the phone. The audio recordings of the interviews were then transcribed, and codified. Data analysis of the interviews began with the iterative development of a coding framework. Thematic network analysis, as recommended by Attride-Stirling for interpreting complex qualitative data, was deemed most appropriate because it allowed for the systematic extraction of common themes and evaluation of the relative importance of each. ${ }^{27}$ Two researchers developed a coding framework by noting common thematic threads surfacing in the responses. The final coding framework was evaluated by a third independent researcher and was used to code the data into thematic groups. Subsequently, these groups were merged into common themes, and used as the basis of this paper.

\section{Demographic Data}

Type of LTS: Figures 1(a) and (b) provide a characterization of LTS activities by types of communities served and type of curricular integration. There were slightly more faculty engaged in international than domestic activities though many were engaged in both domestic and international service. A majority of the faculty interviewed incorporated service into their academic coursework, though a significant number of faculty performed only extracurricular service or used it in addition to curricular initiatives.
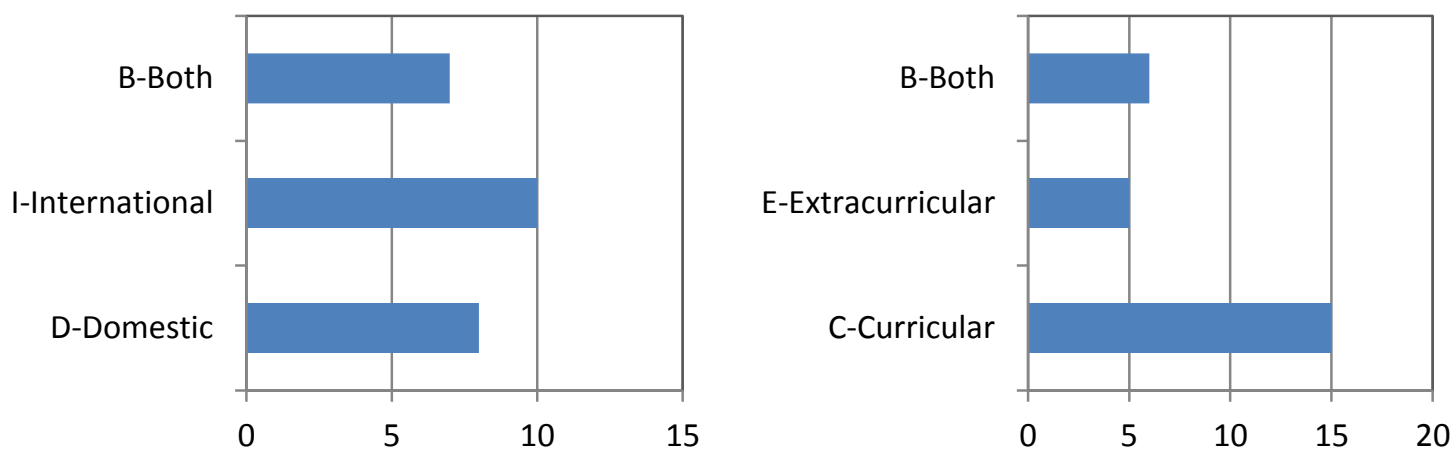

Figure 1: Characterization of LTS activities by

$(a$, left $)$ types of communities served and $(b$, right) type of curricular integration

Participant Gender: Figure 2 provides the number of interviewed faculty according to their gender. Seven of the 27 faculty interviewed were female, (25.9\%). ASEE reports that in 2011 the proportion of female graduating baccalaureate engineers was $17.9 \%$ and the proportion of female faculty was $10.5 \%$. 


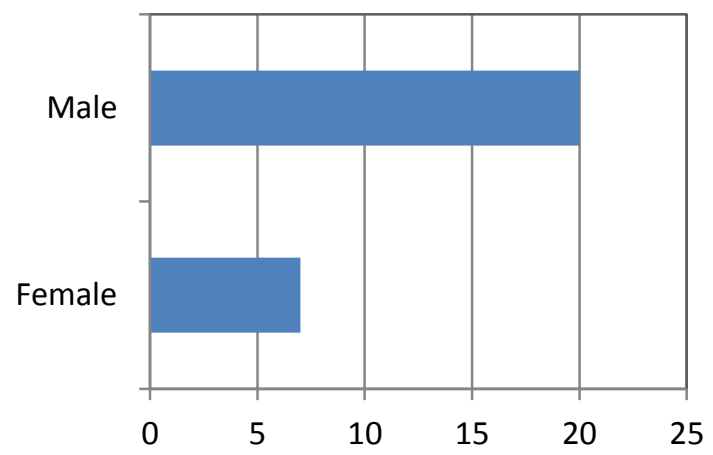

Figure 2: Gender of interviewed faculty engaged in LTS activities

Participant Experience: Figure 3(a) provides an accounting of the rank of the interviewed faculty. Sixteen of the 27 participants were tenured faculty (TTWT-tenure track with tenure) six were on tenure track but without tenure (TTWOT-tenure track without tenure). Two of the interviewed faculty were not on the tenure track while one was an administrator and one had a joined faculty/administrative appointment. Figure 3(b) indicates the years of LTS experience for the interviewed faculty; most of the interviewed faculty had five or more years of experience.
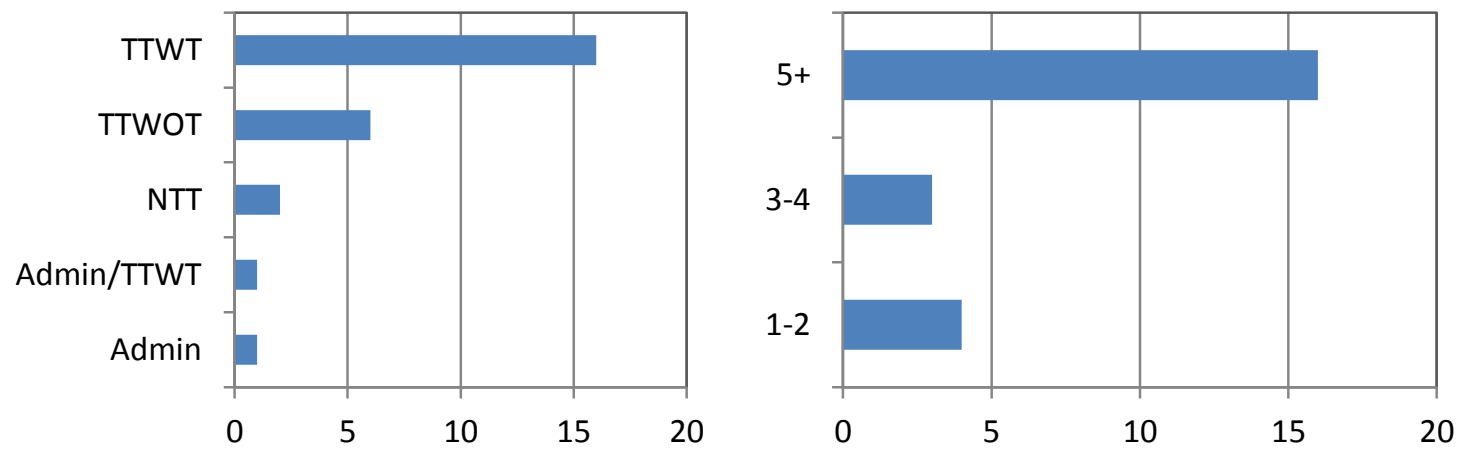

Figure 3: Characterization of interviewed faculty by (a, left) academic rank and (b, right) years of LTS service

Type of Institution: Figure 4 (a) and (b) provides an overview of the type of institutions at which the interviewed faculty were employed. Figure 4(a) indicates that a super majority (20) of the 27 faculty were engaged at research doctoral degree granting institutions (RD) with only a few at research masters (RM) and undergraduate institutions. Figure 4(b) indicates that most of the faculty were employed at public institutions though a significant number were employed at private institutions. 

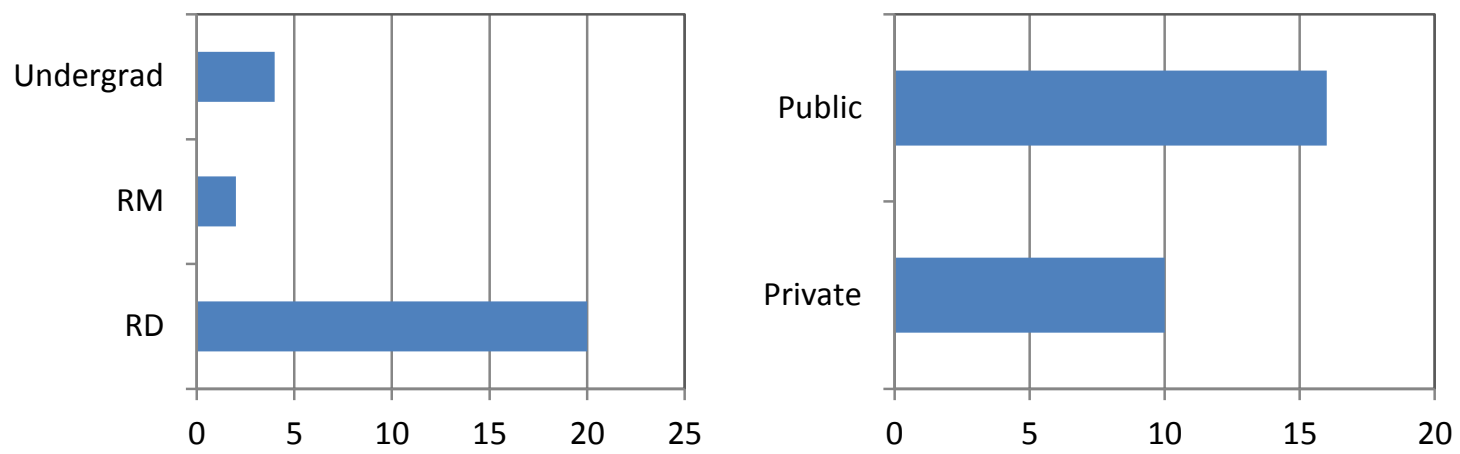

Figure 4: Characterization of participant institutions by (a, left) research intensiveness and (b, right) public charter

Department Characterization: Figure 5 (a) and (b) provides the number of faculty in the departments and percentage of departmental faculty engaged in LTS. It is observed that the size of the participants' departments varied widely. Figure 5(b) suggests that LTS activities are generally practiced by a small number of faculty in any given department (fewer than $25 \%$ ), with only 3 of the 27 participants indicating that more than half of their departmental faculty were engaged in LTS.
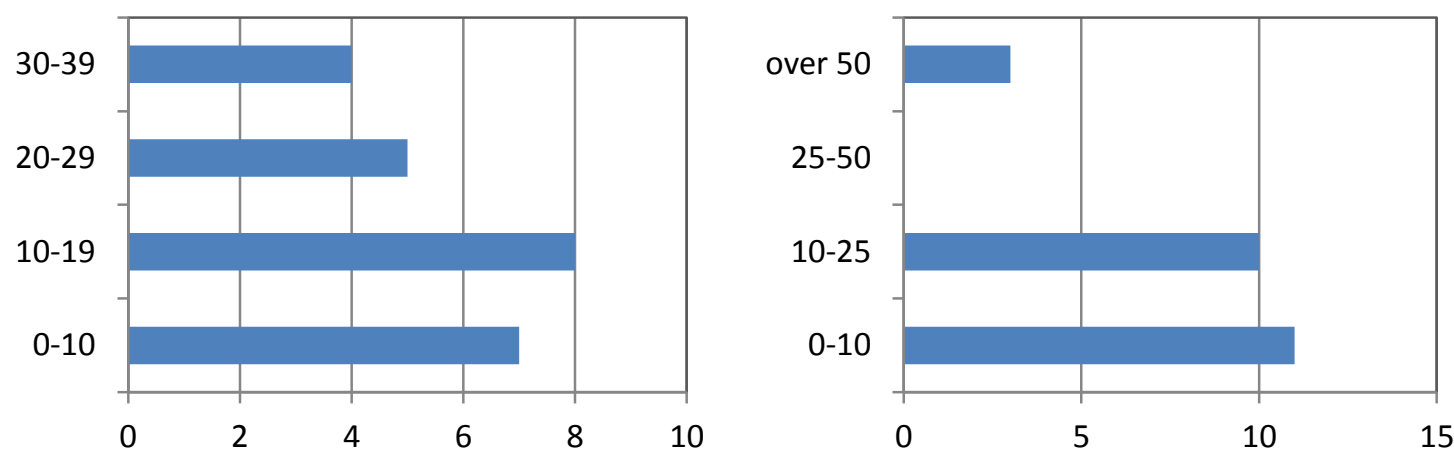

Figure 5: Characterization of participant departments by (a, left) number of faculty and (b, right) percentage of faculty engaged in LTS

Figure 6 provides a list of the program majors with which each interviewed faculty was affiliated. The most common academic majors included civil/environmental engineering, engineering education, general engineering, and mechanical engineering. Many other majors were also engaged in LTS activities, though electrical engineering is a notably absent given its size relative to the engineering population. The faculty in this study taught courses at various levels ranging from freshmen seminars to senior capstones and graduate courses. Some of the courses were interdisciplinary and included multiple instructors. 


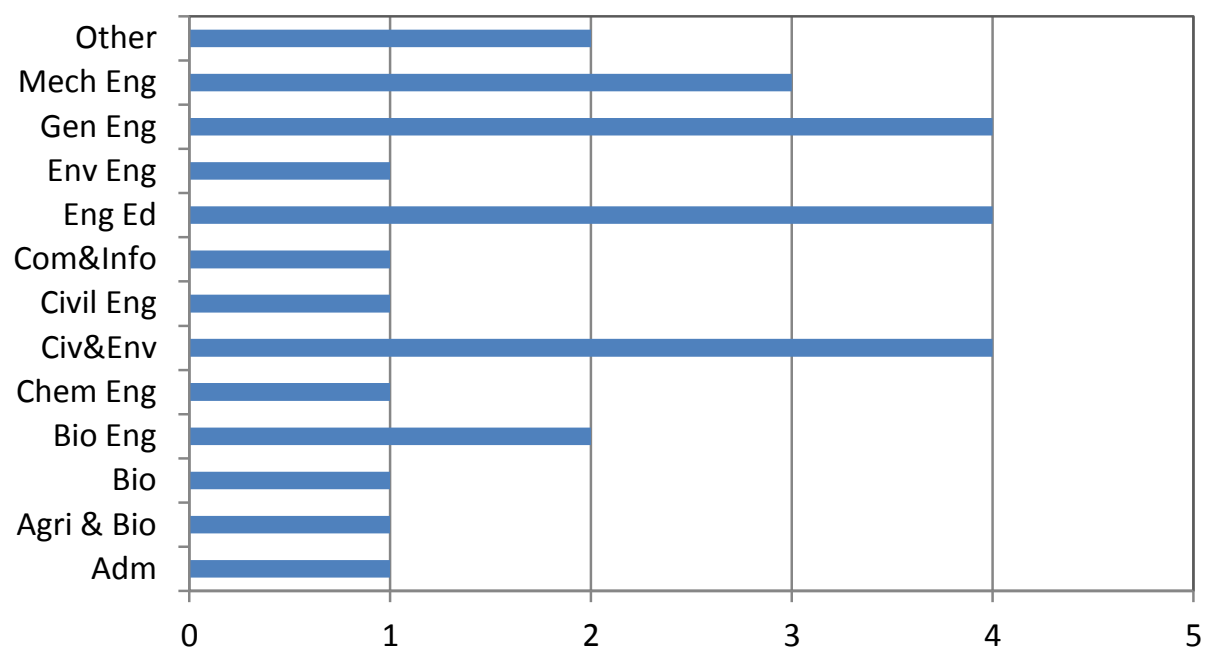

Figure 6: Characterization of participant department majors

It is important to note that learning through service was not utilized in every one of the courses that were taught by the participants, and that the participants did not teach the same number of learning through service courses each year. For the most part, the use of learning through service was rooted in a particular course and not every course taught.

\section{Findings}

Several key themes emerged from the interview data, and they are presented below in three major categories. The first category focuses on why engineering faculty adopt LTS. The second category focuses on how engineering faculty implement LTS. The third category examines factors that hinder the successful implementation of Learning through Service.

\section{Teaching and Learning Goals}

I. To Increase Student Motivation to Learn: Faculty members were interested in learning through service efforts primarily because they viewed it as a way to motivate students to deepen their learning of the academic content of engineering. In their view, students become more motivated to learn and develop technical skills when the learning extends beyond the classroom. As such, the faculty invariably integrated service projects that focused on developing competencies related to their subject matter to ensure students' mastery of technical disciplinary knowledge. Hence, learning through service was viewed as a value-added teaching strategy not only because it motivates students to learn, but also because it helps to develop skilled engineers. For example, one participant states:

"For me this is about adding motivation and showing connection through the real world."

Another states:

"We see greater motivation to be an engineer. Because now they have a belief which I hope is true that engineering can be about serving other people and they can make a difference."

This sentiment was consistent among the faculty as is evident from yet another comment below: 
"I am a firm believer in context as a way to motivate students and also help them understand how what they are learning in the classroom will make a difference in the real world."

The faculty members interviewed are motivated to engage in Learning through Service in order to get students more excited about what they are learning by applying the theory to the "real world". They believed that when students have the opportunity to practice applying their knowledge to real world problems, it can reinforce their motivation to learn.

II. To Enhance Students' Ability to Solve Real World Problems: Although the faculty acknowledged their interest in learning through service stemmed from the fact that it motivated students to learn, they also realized the importance of maintaining focus on the technical side of the discipline to solve real world problems. For example, one states:

"I saw this as a natural bridge between learning about different aspects of engineering and being able to apply them in the real world."

The data suggest faculty engaged in learning through service not only to teach students the competencies necessary for effective practice as engineers, but also to enhance students' understanding of real-world problems. From the perspective of the faculty, it deepens both the didactic and the practical aspects of the subject matter. The study participants were also interested in ensuring that students learn to solve real world problem to improve the lives of others. Most of the international projects took place in resource poor communities to help increase the standard of life for the community members. One participant states:

"this current years' project is actually doing a micro factory layout and a business plan for them to start producing some of the products that we've worked with them on for income generation and skills development and technical training"

Another participant states:

"We work with some villages in Ghana and we are working with them right now to start a business, smokeless cooking fuels. They take biomass corn or something else and they create ethanol and then from the ethanol they gel the ethanol into a thick jelly and they use that to cook."

The faculty motivation for learning through service was not only to motivate students to acquire disciplinary content knowledge, but also determining how and where to extend such knowledge to solve problems in the community. For example, one faculty states:

"I think the students get motivation from findings activities that-all these hands-on activities kids can do in class, but when you present to them activity that has a context in terms of solving a need or solving a problem that somebody has, and they get to actually build."

Another is quoted as saying:

"I've always been intrigued by Service Learning as one possible way to provide students with sort of authentic or realistic learning experiences that more closely mimic what they'll actually experience in doing engineering practice."

Participants were inspired by the fact that learning through service helps students to solve problems in real world settings as opposed to a didactic classroom environment. They viewed this approach as a way to help students understand critical problems facing society, to instill a sense of responsibility in working with the community, and to empower students and communities alike. 


\section{Teaching and Learning Processes}

I. Learning From and With Community Partners: The participants in these interviews engaged students in learning through service efforts in two ways. First was a classic curricular-based model in which students acquired academic credit while applying course concepts to perform service in a given community. The other approach was through extracurricular means in which students engaged in a service project without academic credit. Both of these LTS efforts were intended to take student learning to a deeper and more meaningful level in which students were given the opportunity to learn about a given problem through first-hand experiences with community partners. For example, one faculty states:

"I primarily teach senior capstone design courses and in it what I do is find community agencies or non-profits that have some specific engineering tasks that they would like to help done but either they can't afford it or the clients can't afford it. So I match them up with teams of students and the students then do that as their senior design project." In some instances, the faculty members had students identify the community partners to work with. As noted by another faculty member:

"I had students actually go out and find real clients on their own in the community and they had a set of technical specifications for their projects which met the learning goals of my class and they had to find real projects that they could achieve the technical goals within while also helping a community partner."

The engineering processes varied with levels and goals of the LTS activities, but all involved an open-ended problem solving process in which requirements were defined and different solutions developed.

Interestingly, the majority of LTS efforts were curricular based working in either local or international communities to solve a problem. The local projects were often in communities in which the university is located. In one local community project the faculty states:

"I talk to students about the fact that we're working in site that has superfund area. We talk about the history at the site, how they're contaminated, what the issues are, and what exposure especially for children. So I try to provide them with that information. They can understand the purpose of why it's important. And then we go to the gardens and the students take samples so I think they are also able a little bit to interact with the community, interact with the people who run the gardening organization that's usually there and some community members are there as well."

In one international project, the faculty describes one of many projects in Cameroon below:

"We have been working on one partnership with one community in Cameroon for the past seven years. One of the projects has been a water quality project where we've been looking at bio sand filters to address water quality issues. We've also worked on a water distribution system where - this is actually an area where we have had some engagement in the classrooms because a number of students have used their senior design projects to design different phases of this water distribution system."

There were also extracurricular projects with Engineer without Borders that enabled students to solve problems in resource challenged communities in developing countries.

"I'd say that the way that we run our EWB program here places quite a strong emphasis on working with the community.... because it draws on a skill set that's not often used in engineering coursework. It draws on leadership and project management and people 
skills and communication and a variety of other skills that our best students recognize are important, that they don't get a chance to practice very much within the context of coursework."

By learning with the community locally or internationally to conduct an investigation of a problem, and learning from each other, students were challenged to develop cultural competency by operating in foreign settings while enhancing their technical knowledge.

II. LTS Approach: Faculty had different strategies for how they approached LTS. For example, one respondent states:

"So in the class, we deal with talking about the bottom up, we talk about underserved markets, we talk about social justice, we talk about resource consumption, we talk about sustainability, we talk about social entrepreneurship, we talk about financial sustainability. So we are talking about all these different issues and then we talk a little bit on that the technical aspects of how do you do the engineering design, how do you do ideation, how do you do conceptualization, how do you do per type formation, how do you do evaluation of feasibility studies."

Another respondent states:

"We use the human centered design model. So it's actually integrated in the curriculum and the community, the stakeholders who are the community. In human centered design, understanding of and interacting with the stakeholders is one of the pillars with human centered design and by placing the human centered design model in service learning the students are doing that all the time. So we have about $80-90$ projects going on and we have a curricular structure so the design course, the students come into the design class and we have curricular structure set up that guides students into that interacting with the community."

In addition, as stated by another participant:

"The product design process involves several steps. And I essentially divided it into three big steps. One step is defining or understanding the problem, the next step is developing a concept for a solution, the next step is making a prototype and probably talking about a business venture also around that so they immerse themselves in the community, they take videos, they take pictures, they look at people using some technologies, they look at people, community, their lifestyle, their culture and in terms of global resolve they do it in Ghana, basically Ghana and Mexico right now."

Although the implementation strategies differed, they integrated dimensions that supported engineering systems thinking by looking at engineering solutions that take into account the social, moral, and economic consequences. Lathem (p. 446) states "an engineering curriculum supportive of systems thinking also embraces the tenants of inquiry-based learning and engages students in real-world and active learning experiences". ${ }^{2}$ This approach is based on knowledge, engineering skills, and behavioral competencies that include interpersonal and personal skills.

III. Learning Through Reflection: Reflection is a process of thinking that allows students to critically examine their service experiences. Only two faculty members in this study did not explicitly incorporate reflection in their LTS efforts. However, they were conscious of the fact that their learning through service effort could be improved by taking the time to incorporate reflection into the learning process. One respondent states: 
"That's one of the, weaknesses that I have is the - you know, my involvement with the Campus Compact and it sort of emphasizes the reflections part of the service learning experience."

The other faculty response to the question of integrating reflection in the course requirement is:

"No, I don't. And that's one thing that I would like to maybe change in the future."

Apart from these two faculty members, the participants widely believed that reflection was the key for students to extract meaning from their community learning experience. Therefore, students' analysis of the community experiences through critical reflection was integrated not only in credit bearing courses, but also in extra-curricular activities. However, in extra-curricular cases reflection was not formalized, it was done implicitly through the reporting requirements of community service projects. For example, seven faculty members were engaged in extracurricular projects such as Engineers without Borders, and all of them referred to the report students are required to submit after their service project. One states:

"The National EWB Organization has a structure where they require some reports that our students have to do, and one component of those reports is to consider the community needs, the social aspects, unintended consequences of the project, that sort of thing. So the students do that through the reporting process, but we don't have a formal reflection mechanism."

Although reflection was not done in a formal way for extracurricular projects, based on the reporting requirements, students had the opportunity to reflect on their community service learning experience. However, for the majority of the faculty engaged in curricular LTS, reflection was critical in heightening academic and personal learning. For example, one participant said:

"It's to get the students to connect the course content with the service experience. I think that's a critically important thing... We do a lot of discussion. The students do written reflection kind of throughout the semester and we talk a lot. It's those discussions that lead to different design iterations."

The faculty articulated that reflection enabled students to deepen their understanding of the course content, and develop a broader appreciation of the discipline. One faculty reported that reflection helped to draw out learning about complex systems requiring interdisciplinary approaches:

"The main purpose of reflection is to help them understand that this is a system. It is not a laser focused problem. When you look at any problem in any community you have to look at the community as a system which involves all kinds of disciplines. So the main purpose is to help them understand that you need multiple disciplines to solve any community based problems."

Reflection for some faculty members was intended to help students realize the problems they attempt to solve in the community do not only require an engineering solution, but require multiple approaches.

For the most part, the faculty integrated reflection into their courses in two essential ways. Writing was one of the primary ways in which reflection was exercised especially for credit bearing courses. Invariably faculty required students to write about their community learning 
experiences. In the reflective exercise, students had to write their insights about what linked the course readings and their community experience. The degree of writing was variable (daily, weekly, midterm paper, or final paper). However, students were generally required to write journal reports, making entries every time they went into the field, after meeting with or talking to community partners.

Discussion was another mode of reflection. The faculty in this study actually took time to contemplate with students in groups what it is they have learned. From the faculty perspective, discussion was incorporated into their classes as a way for students to really understand more deeply how their ideas have to be tried out in the real world and then most likely modified. The process forced students to think and talk about both the content of the theory they read and what that theory means in practice. In their view, discussions helped students determine whether the theory was applicable in a given situation. It also helped students to look at the gaps and syntheses between theory and practice.

\section{Barriers}

I. Institutional and Departmental Commitment: There were many challenges at the departmental and institutional levels for most of the participants. One participant states:

"The number one challenge for me is even though my university highly values it, my engineering colleagues, even at my institution they think it's okay that I do it or that one person in the department does it but they think that working on industrial projects is much more valuable. And what I do, they sometimes question "is it really engineering". And so that is a little bit, that's challenging for me because I think engineering for the majority of the world is real engineering and if you can show numbers of people served and I have my own personal goals that I want to reach before I retire, I think this is engineering that's more important than some of the engineering my colleagues are doing which they'll write a journal paper that maybe six people will read. That's the big challenge is acceptance. Is this really what a professor should be doing?"

Another LTS faculty participant states:

"Some of the challenges are institutional. We need to make sure that other faculty members support this initiative so that we can continue to expand these opportunities as part of the core curriculum. So we need to continue to work on that process. Secondly, we need to make sure that the university continues to recognize and support this kind of initiatives so that the faculty are allowed time both to develop these courses, can apply for grants and third, we need other institutional supports like liability issues, legal issues, IRB issues and even risk management so that we can be sure that our students can be protected in this entire process and with the IRB the other faculty are trained in what we are trying to accomplish so that the appropriate IRB review can be facilitated. And in our case as well, we have to work with the IRBs in the other countries."

Another key institutional challenge highlighted was the fact that their LTS effort was not valued within the reward structure at their institutions.

"It tends to be not valued very highly by particular administrators and despite the fact that we're supposed to be in the business of teaching students. And a lot of places, and certainly at ours, it's not valued very highly, or as highly as strict research, publication stuff. So that's the downside." 
Another faculty respondent states:

"At our institution it's not really highly rated, but I enjoy working with the students, and I think I get value from the students and the learning that they're getting."

A few mentioned resistance from students as a challenge, but less so than the departmental and institutional challenges. For example, one faculty states:

"There's this initial student resistance, I don't really want to go out into the community, I don't want to work at a homeless shelter, that sort of resistance. I think students don't know how to make connections between their real world experience and their academic work. So that's challenging for them. And it's been challenging for me too but less so." Another respondent similarly states:

"If you say that there are three categories and each one takes the same amount of time, the engineering students don't want to hear that. They want, when engineering students hear about a problem, they want to start with a design; they want to make a prototype today. They're impatient. But I've forced them into spending, if the courses are yearlong, they spend two months at least trying to understand the problem, understand the communities.

II. Time Requirements: For the majority of the respondents, time was a major challenge. They were cognizant of the fact that the design of good LTS projects that produce an authentic learning experience takes a great deal of time to develop. However, this issue did not deter committed faculty from engaging in LTS efforts. One participant states:

"I can sense that it's going to be a little time consuming mainly because out of all the faculty who are here, the person who has the most experience with embedding Learning Through Service is myself. I can see that as more faculty sort of will see this as being beneficial and that the go-to person is going to become me, and when you're the go-to person, that means that everyone's coming to your office and wanting you to help them out. Now, I'm glad to do it because I think it's beneficial, but it's sort of that initial effort. You always talk about is the initial effort worth it? I do think it's worth it, but it's going to be very time consuming. But, that's okay."

Another states:

"From my experience, it is a lot more time consuming than anything else that I typically do in courses."

Some faculty were overwhelmed by their LTS efforts given the amount of time it takes to coordinate LTS activities. However, they had a strong commitment to the pedagogy and believed that it provided a powerful tool to enhance student learning while addressing problems in society.

III. Developing Collaborations with the Right Community Partner: The majority of the faculty in this study had five plus years of experience with LTS and had well established partnerships with various communities. However, the faculty members with one to two years of experience expressed challenges with establishing community partners for their LTS efforts. One of them states:

"The big thing there is just identifying the community partner that has a need, something that the students can address and also a community partner who can work with the 
students and provide feedback on their project. It seems to me that that's the real challenge."

Another one states:

"I think the major challenges I guess would be finding a project that is small enough to be tackled by the freshmen and a lot of time without kind of blowing past the number of credits assigned to this class while still getting things done that we need to get done in that class."

\section{Discussion}

This section discusses the implications of the findings, followed by a reflection on some of the study's limitations. Additionally, a discussion of the relevance to engineering education, as well as recommendations for future research is presented, followed by conclusions.

\section{Teaching and Learning Goals}

From a curricular standpoint, the faculty members were motivated to integrate LTS efforts in their teaching because of the potential to improve students' learning outcomes in their particular courses, to increase student motivation, and ability to solve real world problems. This is consistent with the literature specifically, with respect to service-learning. Numerous studies on service-learning in higher education have established consistent direct links to student mastery of course content (Eyler \& Giles, 1999). These studies have provided sufficient evidence to indicate that participating in service-learning helps students to understand and apply the course material through application to open-ended problems. When students connect course material to their activities in the community, it increases their ability to grasp course concepts - it is a reinforcing loop.

Despite the fact that faculty engage in LTS efforts to motivate students to learn engineering content and skills, there remains a lack of widespread participation. Faculty participation has often been cited as a major factor in enhancing LTS, but as was demonstrated by the findings only a limited number of faculty members are engaged in LTS efforts in engineering disciplines.

\section{Teaching and Learning Processes}

There were three key themes that emerged here. First, the value of students working with each other and learning from community partners enhanced student leadership and project management skills. Second, faculty used different approaches/conceptual models in introducing their service projects to students. Third, some form of reflection was typically used, though the rigor of the process and the methods varied.

One key understanding from the analysis is that the faculty in this study structured their LTS activities using teaching and learning strategies consistent with democratic learner-centered approaches. These strategies included collaborative learning and problem solving in a specific social setting including reflective practices. A common strategy was collaborative learning, an educational approach to teaching and learning that enables students to work with others to solve problems and understand complex concepts.

As such, students were required to learn with community members (domestically or internationally). Through interaction with the community, students were expected to be able to identify community problems and develop solutions within specific community context. By 
collaborating with community partners in the learning process, students learn to develop intricate understanding of community problems through the lens of the community.

LTS created a learning environment that provided the opportunity for students to learn from each other while working in groups. Hence, by learning with the community to conduct an investigation of a problem, and by also learning from each other, students were challenged to function in community settings outside the classrooms. A collaborative learning framework suggests that there was intentional effort to integrate multiple perspectives to generate new knowledge. Learning from and with others in the classroom, as well as learning with and from others in the community illustrate the fact that learning cannot be achieved in isolation. Instead, learning is achieved in social settings. Students learn not only from their instructors through class discussions, they also learn from other students in the classroom and with community members.

\section{Barriers}

Although the amount of time required to coordinate LTS efforts including identifying the right community partners is overwhelming for faculty interviewed, they remain resolved in their commitment to using this pedagogy. However, the more striking challenge faculty face is the lack of strong departmental support which also has implications for institutional support. Institutional support is clearly related to the values and mission of the institutions. While LTS was not discouraged at the departmental and institutional levels, the majority of the faculty did not feel their efforts were valued at their institutions. It may be useful to survey deans and department chairs to determine what would compel them to support and promote LTS initiatives. Perhaps linking LTS to institutional priories is one key way and another key way is to more thoroughly assess the outcomes in ways that are meaningful in engineering education, especially, ABET identified learning outcomes. Otherwise, LTS becomes simply an individual faculty choice. Although LTS has demonstrated benefits as means for the integration of education for work and citizenship in engineering programs of study in higher education, it has yet to be integrated in a deep and wide manner in the curriculum in higher education, and especially in engineering which has a professional creed to provide service to society.

\section{Conclusions}

Findings from this study echo previous findings ${ }^{28}$ in that engineering faculty strangely perceive LTS as increasing student motivation to learn disciplinary content. The findings indicate that helping students to deepen their learning of engineering course content was critical for faculty. Similarly, this is consistent with past studies on faculty motivation for service-learning in various disciplines. ${ }^{29-32}$ However, like this present study on LTS, Pierrakos et al reported engineering faculty engaged in LTS efforts perceived LTS experiences as motivation for students to meet course and program objectives. ${ }^{28}$ Yet, the contribution of this study to the body of literature is the faculty desire to enhance students' ability to solve real world problems through curricular and extracurricular programs.

These findings are limited by the nature of the sample. This study reveals extracurricular programs such as Engineers without Borders are structured with reflection that encompasses a written report about the community service experience. However, this study does not shed any light on whether students' mastery of course content as a result of LTS is as evident as with 
service-learning. Further analysis and investigation is required to extract and validate the primary themes as a function of respondent demographics towards the development of appropriate recommendations and policies.

\section{Bibliography}

${ }^{1}$ National Science Foundation (NSF) 2007 Moving Forward to Improve Engineering Education (No NSB-07-122) Washington, DC: National Science Foundation.

${ }^{2}$ Lathem, S. A., NEUMANN, M. D., \& Hayden, N. (2011). The Socially Responsible Engineer: Assessing Student Attitudes of Roles and Responsibilities. Journal of Engineering Education, 100(3), 444-474.

${ }^{3}$ Vanasupa, L., et al. (2006) Global Challenges as Inspiration: A Classroom strategy to foster social responsibility. Science and Engineering Ethics, 12(2), 373-380.

${ }^{4}$ Bielefeldt, A. \& Pearce, J. in Colledge (Ed.) (2012) Convergence: Philosophies and Pedagogies for Developing the Next Generation of Humanitarian Engineers and Social Entrepreneurs. International Journal for Service-Learning in Engineering.

${ }^{5}$ Swan, Christopher W., Kurt G. Paterson, and Angela R. Bielefeldt. "Panel-measuring the impacts of project-based service learning in engineering education." In IEEE Frontiers in Education Conference, 2009.

${ }^{6}$ Coyle, E. et al. (Fall) 1997 "EPICS: A Model for Integrating Service-learning into the Engineering Curriculum.” Michigan Journal of Community Service-Learning 4:81-89.

${ }^{7}$ Oakes, William. "Service-learning in engineering: A resource guidebook." Providence, RI: Campus Compact. 2004.

${ }^{8}$ Tsang, E. (Ed.). 2000. Projects that matter. Concepts and models for service-learning in

${ }^{9}$ Lima, M. \& Oakes, W. (2006) Service-Learning Engineering in the Community. Great Lakes Press, Inc.

${ }^{10}$ Colledge, T. (Ed.) ( 2012) Convergence: Philosophies and Pedagogies for Developing the Next Generation of Humanitarian Engineers and Social Entrepreneurs. International Journal for Service-Learning in Engineering.

${ }^{11}$ Johnson, D., Johnson, R., \& Smith, K. (1991) Cooperative Learning. HSHE-ERIC Higher Education Reports, Washington, D.C. The George Washington University, School of Education Human Development.

${ }^{12}$ Barr, R. B., \& Tagg, J. A New Paradigm for Undergraduate Education in November/December 1995, Change Magazine.

${ }^{13}$ Zlotkowski, E. (1999) Pedagogy and Engagement, in Bringle, R., Games, R, Molley, E., (Eds) College and Universities as Citizens (pp.96-120), Boston: Allyn \& Bacons. 
${ }^{14}$ Erickson, J., \& Anderson, editors (1997) Learning with the Community, Concepts and Models for Service-Learning in Teacher Education, Washington, D.C. American Association for Higher Education.

${ }^{15}$ Morton, K. \& Troppe, M. (1996). From margin to Mainstream: Campus Compact's project on integrating service with academic study. Two cases of institutionalizing service-Learning: How campus climate affects the change process. Providence: Campus Compact.

${ }^{16}$ Jacoby, B. (1996) Service-learning in today's higher education. In B. Jocoby and Associates. (Eds.) Service-Learning in Higher Education: Concepts and Practices. San Francisco: John Wiley \& Sons/ Jossey Bass.

${ }^{17}$ Marullo, S. (1997). “The Service-Learning Movement in Higher Education: An American Response to Troubled Times." Sociological Imagination 33: 117-137.

${ }^{18}$ Bringle, R. G., \& Hatcher, J. A. (1995) A Service-Learning Curriculum for Faculty, The Michigan Journal of Community Service-Learning, Fall, 1995, pp.112-122.

${ }^{19}$ Stanton, T., Giles, D. Jr., and Cruz, N. (1999) Service-Learning: A Movement's Pioneers Reflect on its Origins, Practice and Future. San Francisco, CA: Jossey-Bass.

${ }^{20}$ Hepburn, M. A., (2000) Service-learning and Civic Education in the Schools: What Does Recent Research Tell Us?. In Mann, S. \& Patrick, J. J. (Eds.) Education for Civic Engagement in Democracy, Service-learning and other Promising Practices, pp. 45-59.

${ }^{21}$ Duffy, J., Barrington, L., Reynaud, E., \& Heredia, M. (2012). What do Students Think about Service-Learning in Required Engineering Courses? .ASEE 2012 Annual Conference Proceedings. AC 2012-5524. American Society of Engineering Education.

${ }^{22}$ Reynaud, E., Duffy, J., Barrington, L., Rhoads, J., Kazmer, D., \& Tucker, B. (2012). Engineering Faculty Attitudes towards Service-Learning. ASEE 2012 Annual Conference Proceedings. AC 2012-4134. American Society of Engineering Education.

${ }^{23}$ Duffy, J., Barrington, L., West, C., Heredia, M., \& Barry, C. (2011). Service-Learning Integrated throughout a College of Engineering (SLICE). Advances in Engineering Education , 2 (4).

${ }^{24}$ Huilman et at, (2005) Service-learning in engineering: a valuable pedagogy for meeting learning objectives Journal of Engineering Education Vol. 30 No. 2 May 2005, 155-165.

${ }^{25}$ Yin, R. K. (2003) Applications of case study research. Thousand Oaks: Sage Publications.

${ }^{26}$ Merriam, S. B. (1998). Qualitative research and case study applications in education. San Francisco, CA: Jossey-Bass Publishers.

${ }^{27}$ Attride-Stirling, J. (2001). Thematic networks: an analytic tool for qualitative research. Qualitative Research, 1(3), 385-405.

28 Pierrakos,O., Zilberberg, A., Swan, C. W., Bielefeldt, A. R., Paterson, K., Duffy, J. J., \& Mcvay, S., Faculty Survey on Learning through Service: Development and Initial Findings, 2012 ASEE Annual Conference.

${ }^{29}$ Hammond, C. (1994) Faculty motivation and satisfaction in Michigan higher education. Michigan Journal of Community Service Learning, 1 42-49. 
${ }^{30}$ Banerjee. M., \& Hausafus, C., (2007) Faculty use of service-learning: perception, motivations, and impediments for human services. Michigan Journal of Community Service Learning 14(1) $32-45$.

${ }^{31}$ Abes, E.S., Jackson, G., \& Jones, S. (2002) Factors that motivate and deter faculty use of service. Michigan Journal of Community Service Learning, 9(1) 5-7.

${ }^{32}$ Mckay, V.C. \& Rozee, P.D. (2004) Characteristics of faculty who adopt community servicelearning. Michigan Journal of Community Service-Learning 10(2) 21-33. 